\title{
Country rankings on the scientific production in endocrinology and diabetology
}

\author{
Alessandro Mantovani ${ }^{*}{ }^{*}$, Elisabetta Rinaldi ${ }^{1}$, Chiara Zusi ${ }^{1,2}$ \\ ${ }^{1}$ Section of Endocrinology, Diabetes and Metabolism, Department of Medicine, University and Azienda Ospedaliera Universitaria \\ Integrata of Verona, 37126 Verona, Italy \\ ${ }^{2}$ Pediatric Diabetes and Metabolic Disorders Unit, Department of Surgical Sciences, Dentistry, Pediatrics, and Gynaecology, \\ University Hospital of Verona, 37126 Verona, Italy
}

*Correspondence: Alessandro Mantovani, Diabetes and Metabolism, Section of Endocrinology, Department of Medicine, University and Azienda Ospedaliera Universitaria Integrata, Piazzale Stefani 1, 37126 Verona, Italy. alessandro.mantovani@ univr.it

Academic Editor: Lindsay A. Farrer, Boston University School of Medicine, USA

Received: August 16, 2020 Accepted: September 15, 2020 Published: October 30, 2020

Cite this article: Mantovani A, Rinaldi E, Zusi C. Country rankings on the scientific production in endocrinology and diabetology. Explor Med. 2020;1:307-13. https://doi.org/10.37349/emed.2020.00020

Diabetes represents a major global health problem. It was estimated that the global prevalence of diabetes in 2019 was approximately $9 \%$, with the worrying projection to increase up to $11 \%$ by 2045 [1]. Importantly, it was also calculated that in 2016 worldwide nearly 1.6 million deaths were directly related to diabetes or high blood glucose [1]. In parallel, other important endocrinological diseases, such as obesity, thyroid diseases (i.e., hyperthyroidism, hypothyroidism, and cancer), polycystic ovary syndrome, and infertility, have a relevant clinical and socio-economic impact worldwide $[2,3]$. These data strongly suggest that an additional uplift in research efforts is necessary in this area.

Over the last years, bibliometric studies have been performed in order to evaluate the research productivity and quality of different countries in many scientific fields [4]. However, updated information on the scientific productivity and quality of different countries in the Endocrinology and Diabetology field is lacking. Therefore, the main aims of this report were: (a) to compare the publication productivity of scientific research in the Endocrinology and Diabetology field among various countries in a sufficient period of time; (b) to put in relation the scientific productivity of various countries with their gross domestic product (GDP, which is the monetary value of all finished goods and services made within a country during a specific period and provides an economic snapshot of a country [5]), the percentage of GDP spent in research and development and the number of researchers per million people; and (c) to compare the quality of scientific research among various countries using the citation counts and total H-index (that can be used as indirect markers of research quality). Information regarding the publication productivity was obtained by the SCImago website [6]. Briefly, SCImago is an online platform that ranks journals and countries in several fields based on various bibliometric markers, including total documents per year, citable documents, cites per document, and H-index. The ranking is performed using Elsevier's subscription-based Scopus database. Specifically, we obtained the aforementioned information in the Endocrinology and Diabetology field between 1996 and 2018. For such period, we also acquired information regarding the GDP, the percentage of GDP spent in research and development, and the number of researchers per million people for various countries by 
the World Bank Group website [7]. The main bibliometric and economic parameters for 173 countries are reported in Supplementary Table 1.

Figure 1 reports the comparison of outputs of endocrinology and diabetes research papers among the top eight countries, between 1996 and 2018, in relation to the GDP (Figure 1A), the percentage of GDP spent in research and development (Figure 1B), the number of researchers per million people (Figure 1C) and the citation counts (Figure 1D). As reported in Figure 1A, from 1996 to 2018, the USA was the leader regarding the outputs of endocrinology and diabetes research papers in relation to their GDP, followed by the UK, Italy, Germany, Japan, France, Canada, and China. Interestingly, when compared to other countries, Italy had one of the highest outputs of endocrinology and diabetes research papers with one of the lowest GDP. Respecting the percentage of GDP spent in research and development, from 1996 to 2018, Italy was also one of the main scientific producers of research papers in the Endocrinology and Diabetology field with one of the lowest percentage of GDP spent in research and development (Figure 1B). Similar considerations can be done for the outputs of endocrinology and diabetes research papers in relation to the number of researchers per million people (Figure 1C) and citation counts (Figure 1D).

Figure 2 shows the trend in terms of the outputs of endocrinology and diabetes research papers, between 2010 and 2018, for top 5 countries. Again, the USA was the leader regarding the outputs of endocrinology and diabetes research papers over time. Notably, China was the country that has had a significant increase in scientific productivity in the field of endocrinology and diabetes in the period under consideration, while Italy was in the top four positions, preceded only by the USA, the UK, and China.

The scatterplot matrices of principal bibliometric and economic parameters in 173 countries regarding the outputs of Endocrinology and diabetes research between 1996 and 2018 is reported in Figure 3.

From our report, it clearly emerges that the quantity (i.e., total documents) and quality (i.e., citations and total H-index) of the Endocrinology and diabetes research are broadly associated with GDP, percentage of GDP spent in research and development and the number of researchers for million people for most countries, with important exceptions. One of these is certainly Italy. In fact, the quantity and quality of science produced in Italy in the Endocrinology and Diabetology field are relatively higher than expected, especially considering the percentage of GDP spent in research and development and the number of researchers per million people of this country. Indirectly, this fact displays the excellent preparation and inventiveness of Italian researchers. In other words, Italy still occupies a relevant position on the international scientific panorama in the Endocrinology and Diabetology field, with considerable efficiency and quality in scientific production, despite numerous difficulties. Among them, it is important to remember that, in our country, the number of researchers is still small [8,9], academic hiring practices is often complicated, many researchers tend to expatriate or abandon their research, public research funding is often insufficient, there is a lack of flexibility and immediacy in the availability of resources and an absence of long-term planning, the economic management of funding is made difficult by an excess of bureaucratization and incomprehensible rules [10], and, lastly, the allocation of funding is not fully respectful of merit $[11,12]$. In contrast to other countries, Italy has failed to modernize its scientific system $[11,12]$. This situation is destined to collapse over time, but it may be also an opportunity $[11,12]$. Along with other researchers $[11,12]$, in fact, we believe that some important reforms are urgently needed, such as an independent, public research foundation that supports centers of excellence as part of the European and international network, the reduction of bureaucracy and unjustified rules, the distribution of public funds to the universities based on the performance of the teaching and the research faculty that should be assessed independently.

Our updated results are substantially in line with some previous studies [4, 13]. For instance, in 2015, analyzing a total of 79, 394 articles published on Endocrinology and metabolism from 2010 to 2014, Zhao et al. [13] reported that authors in the USA published the most articles, followed by China, Italy, the UK, and Japan. In addition, in that study, a positive correlation between the number of publications and GDP was observed [13]. 

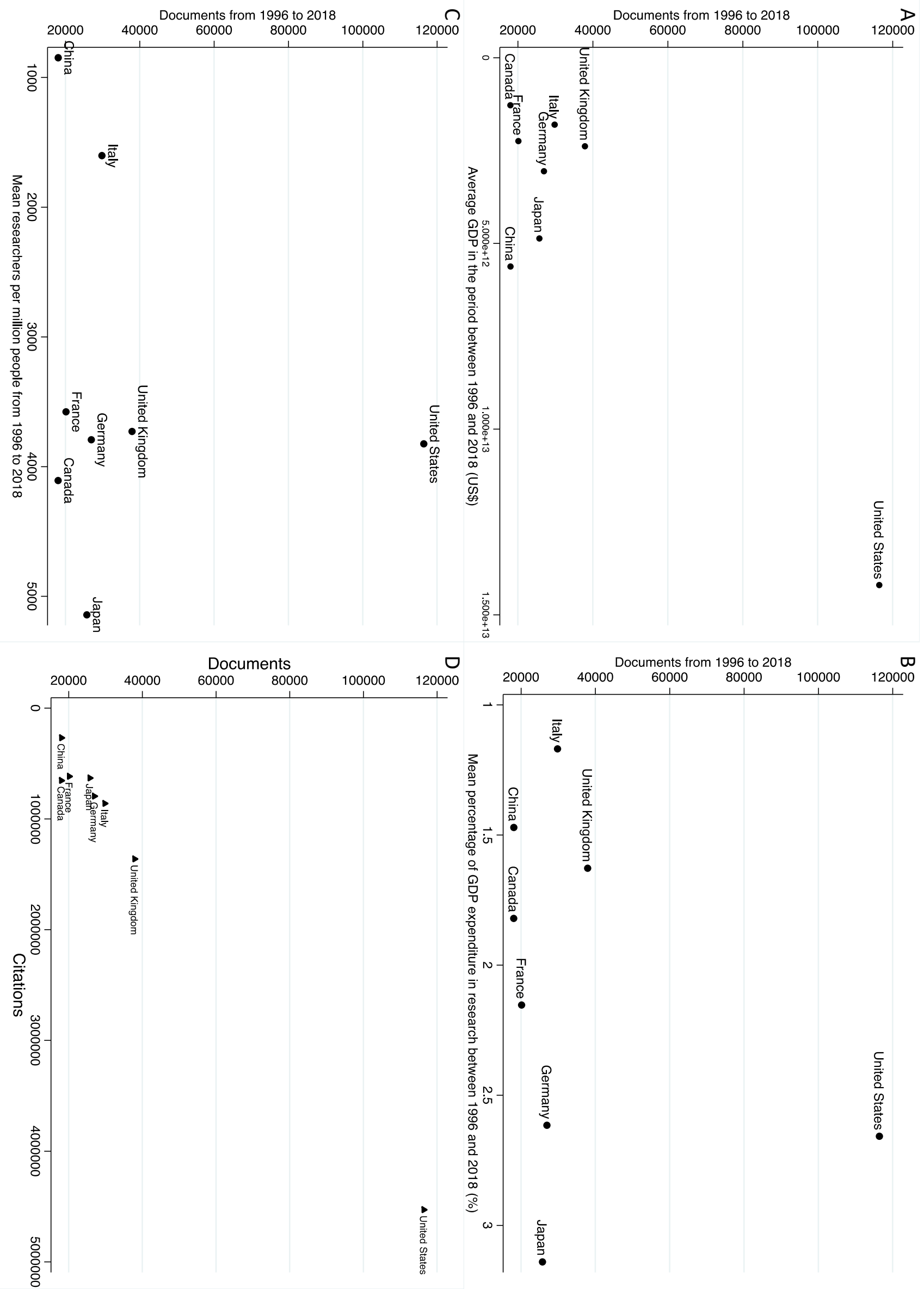

Figure 1. Outputs of endocrinology and diabetes research papers among the top eight countries, between 1996 and 2018 , in relation to the mean GDP (A), the percentage of GDP spent in research and development $(B)$, the number of researchers per million people $(C)$ and the citation counts $(D)$ 


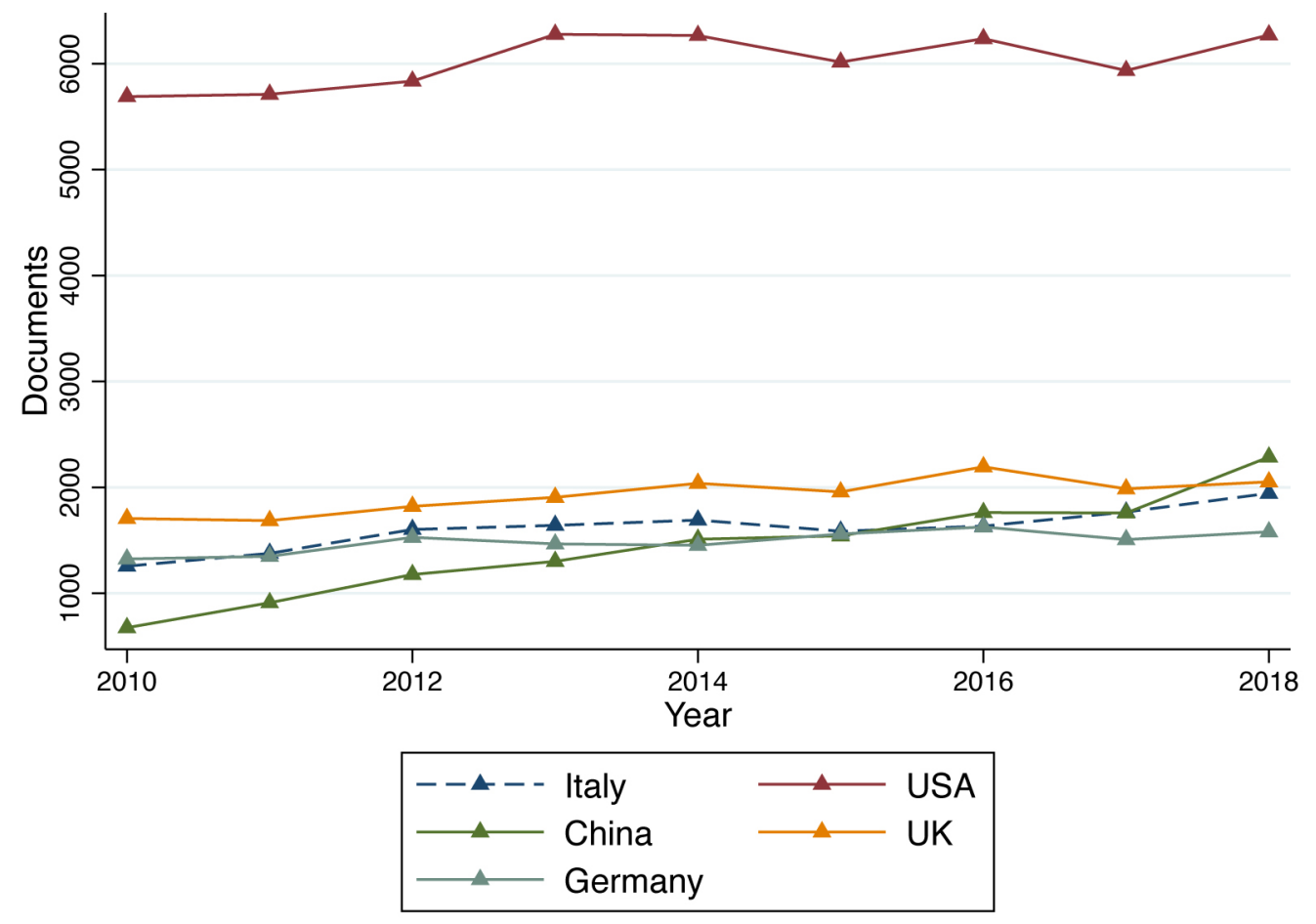

Figure 2. Trends in the outputs of endocrinology and diabetes research papers, between 2010 and 2018, for the top five countries

Our report has important limitations. First, for many countries in which the main language of publication is not English, clinical research articles may be under-represented in the bibliographic databases [4]. Hence, a potential language bias may not be excluded completely [4]. Second, we were unable to evaluate the specific research article funds in the Endocrinology and Diabetology field for each country. Third, we have not specifically addressed the potential impact of each research, with the exception of the citation counts and total H-index that have, however, some important limits $[4,14,15]$.

In conclusion, our report documents that, for most countries, the quantity and quality of science are largely linked to some specific economic parameters, such as the GDP and the percentage of GDP spent in research and development, but also to the number of researchers for million people. However, in this regard, there are important peculiarities. One of them is surely Italy. The quantity and quality of science produced in Italy in the Endocrinology and diabetology filed are relevant, despite numerous impediments that researchers have to face every day. Given that the work of researchers is crucial to guaranteeing an adequate technological and cultural innovation that represents one of the main drivers of all modern and civil societies, a significant boost in the modernization of scientific system in most countries (including Italy) is urgently required. 


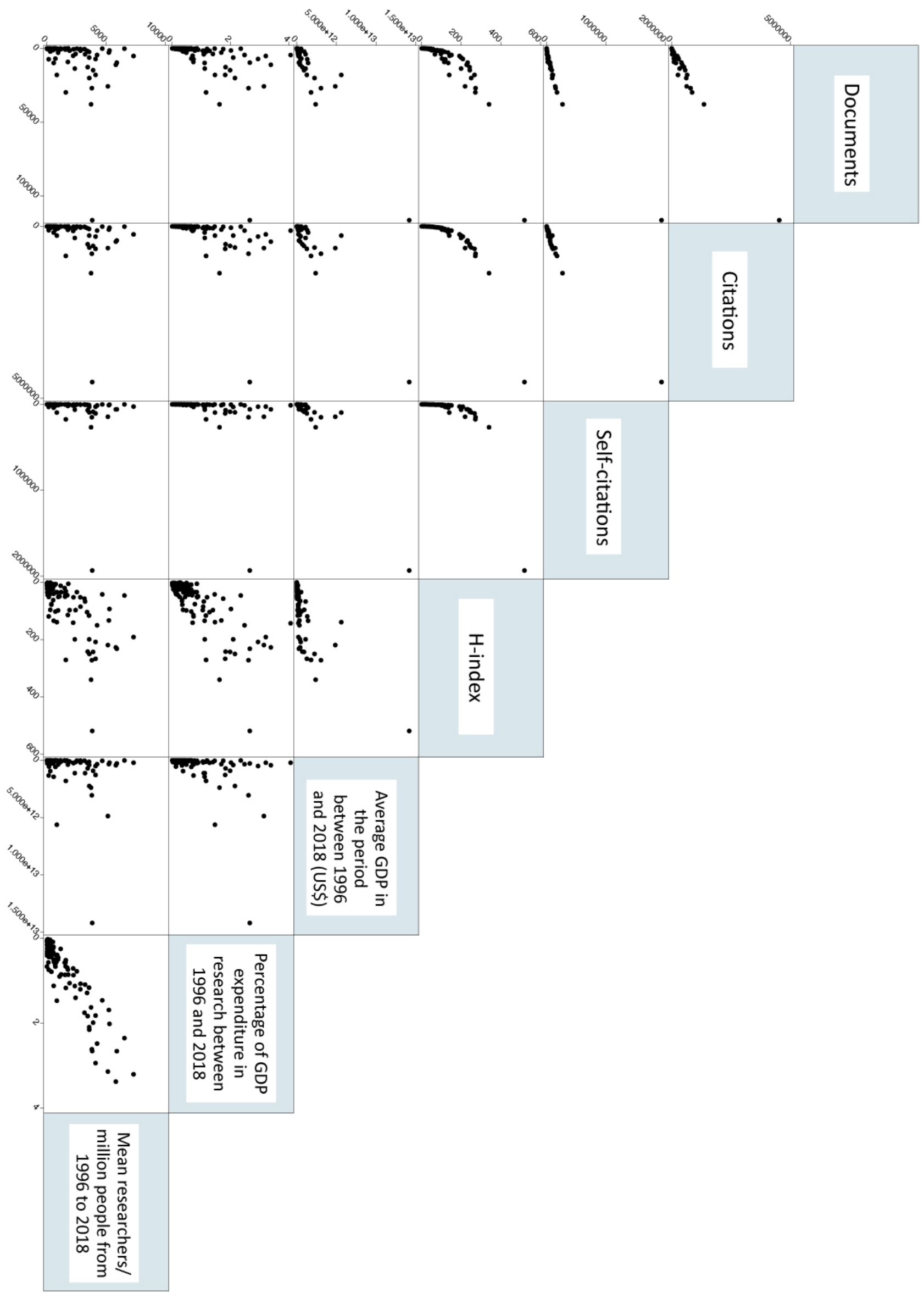

Figure 3. Scatterplot matrices of bibliometric and economic parameters in 173 countries regarding the outputs of endocrinology and diabetes research from 1996 to 2018 


\section{Abbreviations}

GDP: gross domestic product

\section{Supplementary materials}

The supplementary material for this article is available at: https://www.explorationpub.com/uploads/ Article/file/100120_sup_1.pdf.

\section{Declarations}

\section{Author contributions}

AM, ER, and CZ contributed conception and design of the study; AM organized the database; AM performed the statistical analysis; AM wrote the first draft of the manuscript; AM, ER, and CZ wrote sections of the manuscript. All authors contributed to manuscript revision, read and approved the submitted version.

\section{Conflicts of interest}

The authors declare that they have no conflicts of interest.

\section{Ethical approval}

Not applicable.

\section{Consent to participate}

Not applicable.

\section{Consent to publication}

Not applicable.

\section{Availability of data and materials}

Not applicable.

\section{Funding}

Not applicable.

\section{Copyright}

(c) The Author(s) 2020.

\section{References}

1. Saeedi P, Petersohn I, Salpea P, Malanda B, Karuranga S, Unwin N, et al; IDF Diabetes Atlas Committee. Global and regional diabetes prevalence estimates for 2019 and projections for 2030 and 2045: results from the International Diabetes Federation Diabetes Atlas, 9th edition. Diabetes Res Clin Pract. 2019;157:107843.

2. Barrows CE, Belle JM, Fleishman A, Lubitz CC, James BC. Financial burden of thyroid cancer in the United States: an estimate of economic and psychological hardship among thyroid cancer survivors. Surgery. 2020;167:378-84.

3. Patel M. The socioeconomic impact of infertility on women in developing countries. Facts Views Vis Obgyn. 2016;8:59-61.

4. Begum M, Lewison G, Sommariva S, Ciani O, Tarricone R, Sullivan R. European diabetes research and its funding, 2002-2013. Diabet Med. 2017;34:1354-60.

5. Moyer B, Dunn A. Measuring the Gross Domestic Product (GDP): the ultimate data science project. Harv Data Sci Rev. 2020;2. 
6. SCImago, (n.d.). SJR - SCImago Journal \& Country Rank [Internet]. Scimago Lab; c2007-2020 [cited 2020 Jul 18]. Available from: https://www.scimagojr.com

7. World Bank national accounts data, and OECD National Accounts data files - GDP (current US\$) [Internet]. The World Bank Group; c2020 [cited 2020 Jul 18]. Available from: https://data.worldbank. org/indicator/NY.GDP.MKTP.CD

8. Researchers in R\&D (per million people) (People) [Internet]. StatNano.com [cited 2020 Jul 18]. Available from: https://statnano.com/report/s90

9. OECD Chart: Researchers [Internet]. OECD [cited 2020 Jul 18]. Available from: https://data.oecd.org/ $\mathrm{rd} /$ researchers.htm

10. OECD Skills Strategy Diagnostic Report: Italy [Internet]. OECD; c2017 [cited 2020 Jul 18]. Available from: https://www.oecd.org/skills/nationalskillsstrategies/Diagnostic-report-Italy.pdf

11. Abbott A. Italian election leaves science out in the cold. Nature. 2018;554:411-2.

12. Melino G. Order must spring from chaos in Italian research. Nature. 2018;556:436.

13. Zhao X, Ye R, Zhao L, Lin $Y$, Huang $W$, He X, et al. Worldwide research productivity in the field of endocrinology and metabolism--a bibliometric analysis. Endokrynol Pol. 2015;66:434-42.

14. Baccini A, De Nicolao G, Petrovich E. Citation gaming induced by bibliometric evaluation: a country-level comparative analysis. PLoS One. 2019;14:e0221212.

15. Patel VM, Ashrafian H, Almoudaris A, Makanjuola J, Bucciarelli-Ducci C, Darzi A, et al. Measuring academic performance for healthcare researchers with the $\mathrm{H}$ index: which search tool should be used? Med Princ Pract. 2013;22:178-83. 